\title{
Systematic review and meta-analysis of the seroprevalence of West Nile virus in equids in Europe between 2001 and 2018
}

\author{
MARINE METZ ${ }^{1}$, Olaolu Olufemi ${ }^{2}$, Janet Daly ${ }^{3}$, and Marta Barba ${ }^{1}$ \\ ${ }^{1} \mathrm{CEU}$ Universidad Cardenal Herrera \\ ${ }^{2}$ University of Nottingham \\ ${ }^{3}$ School of Veterinary Medicine and Science, University of Nottingham,UK
}

August 25, 2020

\begin{abstract}
There is some evidence that West Nile virus (WNV), which causes encephalomyelitis in equids, is an emerging disease in Europe. The aim of this study was to perform a systematic review and meta-analysis to determine the seroprevalence of West Nile virus in equids in European countries between 2001 and 2018. Two electronic databases, PubMed and Scopus, were searched for relevant publications published from 2001 to 2018 using predetermined keywords. A total of 1484 papers was initially found. After applying the eligibility criteria, 39 papers were finally included in the systematic review. Analysis of 28,089 equids from 16 European countries revealed a pooled seroprevalence of $8 \%(95 \%$ CI $5-12 \%, \mathrm{P}<0.001, \mathrm{I} 2=99.3 \%)$ in Europe. The pooled seroprevalence was slightly higher in Mediterranean basin countries than other countries and when calculated for samples collected between 2001 and 2009 compared to 2010 to 2018. Differences in study design (e.g. sampling associated with recent outbreaks of WNV) contributed to a high degree of variability among studies. Further studies with harmonized study design and reporting of the results are recommended to better estimate and monitor European seroprevalence of West Nile virus in equids.
\end{abstract}

\section{Hosted file}

Systematic review and metaanalysis WNV in Europe for submission 23_08_2020 MBR (1).pdf available at https://authorea.com/users/353718/articles/477491-systematic-review-and-metaanalysis-of-the-seroprevalence-of-west-nile-virus-in-equids-in-europe-between-2001-and2018 
FLOW DIAGRAM OF SEARCH STRATEGY

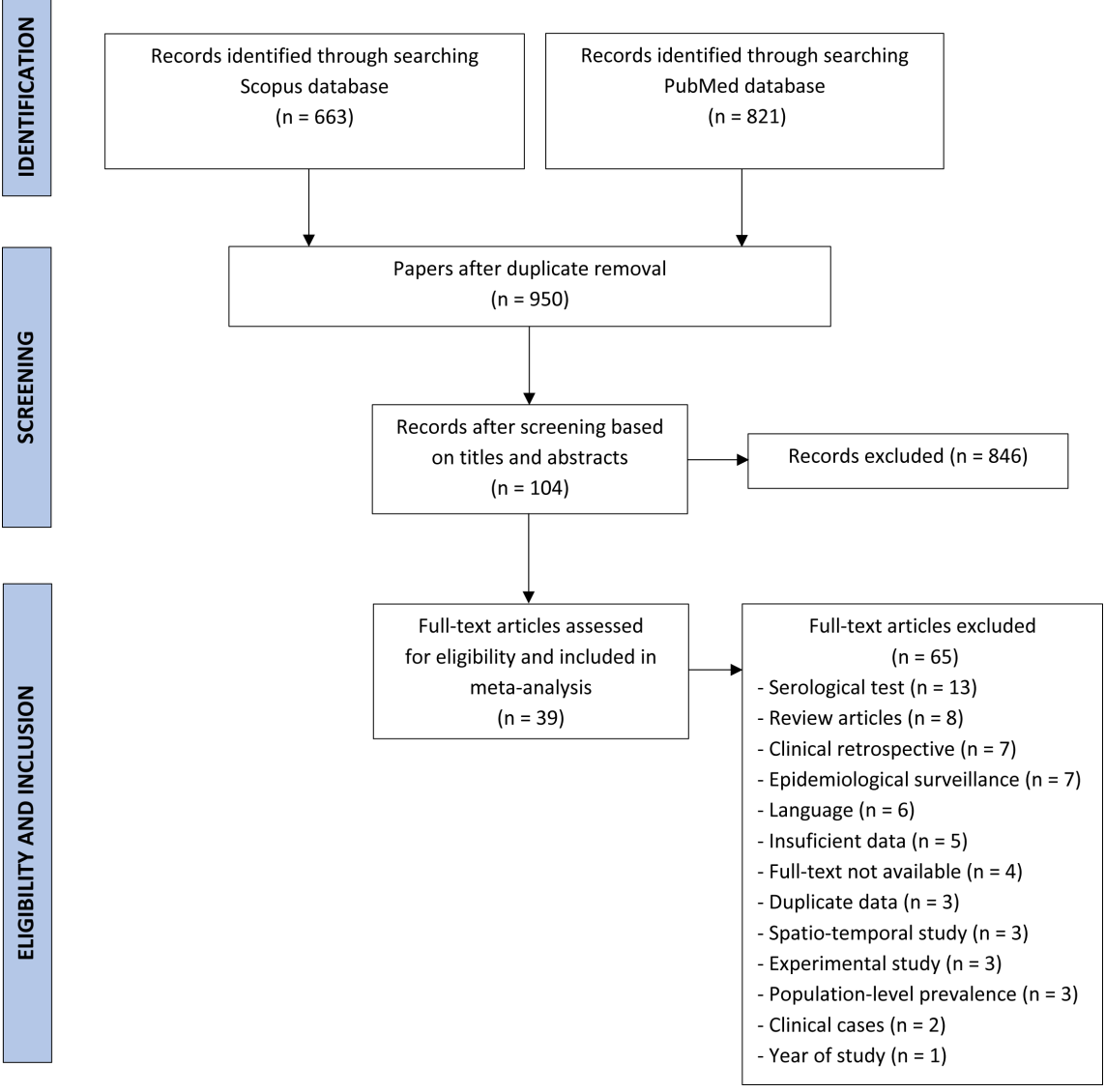



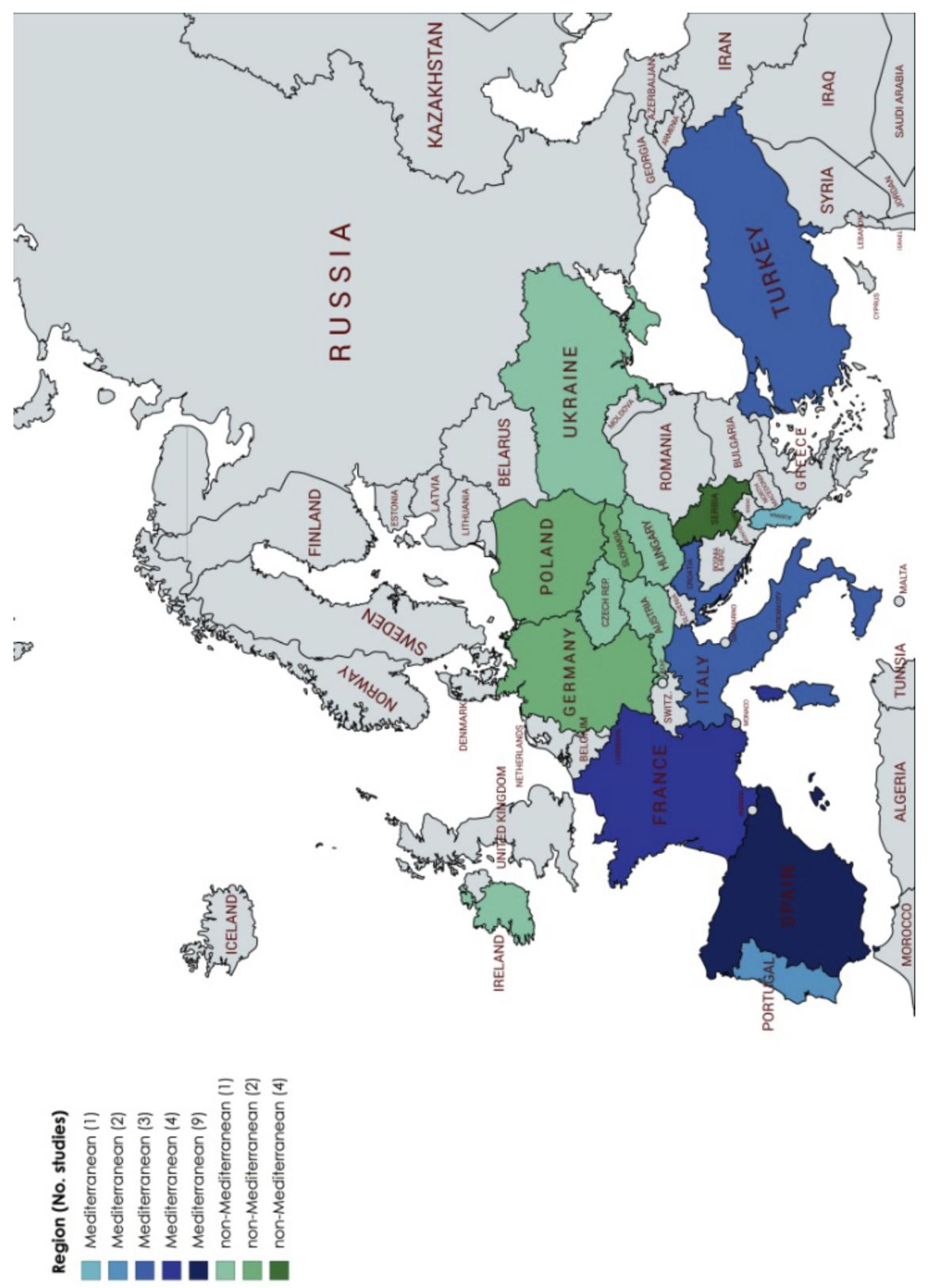

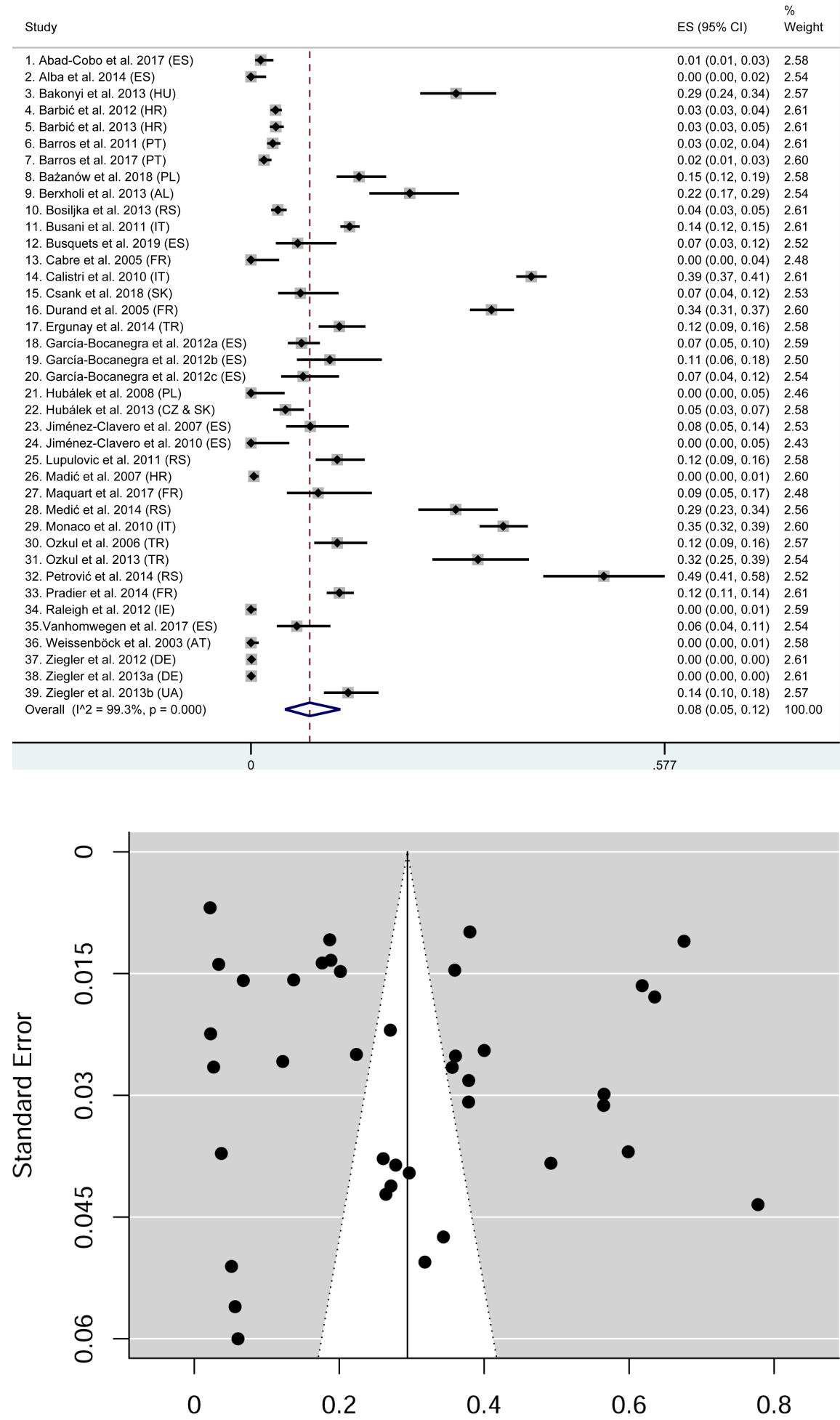

Double Arcsine Transformed Proportion 